\title{
Settlement and Social Capital: Strengthening Futures for Newcomer Children and Society
}

Judith Colbert

RCIS Working Paper No. 2013/5

October 2013

SERIES EDITOR

Harald Bauder

Ryerson Centre for Immigration \& Settlement Ryerson University Jorgenson Hall, 620 350 Victoria Street, Toronto, ON M5B2K3 http://www.ryerson.ca/rcis 


\title{
RCIS Working Paper
}

No. $2013 / 5$

\section{Settlement and Social Capital: Strengthening Futures for Newcomer Children and Society}

\author{
Judith Colbert \\ Consultant
}

Series Editor: Harald Bauder

RCIS Working Papers present scholarly research of all disciplines on issues related to immigration and settlement. The purpose is to stimulate discussion and collect feedback. The views expressed by the author(s) do not necessarily reflect those of $\mathrm{RCIS}$. For a complete list of RCIS publications, visit www.ryerson.ca/rcis

ISSN: 1929-9915

This RCIS Working Paper was presented at the 2013 RCIS conference "Immigration and Settlement: Precarious Futures?" held at Ryerson University, May 15-17, 2013. This publication and the conference received funding from the Social Sciences and Humanities Research Council of Canada. 


\begin{abstract}
The concept of social capital may serve as a framework for supporting the settlement of newcomer children. Social capital may be an especially important asset for newcomers, though its value depends on the extent to which it supports social norms and the willingness of social institutions, like schools, to resist exclusionary practices. Research confirms a positive relationship between parents' social capital and children's wellbeing, although analysis suggests that indicators reflecting US upper-middle class norms may have limited application for newcomer populations. Other research shows that even at a young age, children are capable of building their own social capital. Efforts to help newcomer children accumulate their own social capital have the potential to support their successful settlement, leading to positive shortand long- term outcomes for them and their families while reducing the likelihood of precarious futures for all members of society.
\end{abstract}

Key Words: social capital, newcomer children, settlement, family, community

\title{
Introduction
}

The goal of this paper is to explore the concept of social capital and its relevance to the settlement of young newcomers. First, I will examine definitions of social capital and the reasons why building social capital is important for individuals and society as a whole, but particularly for immigrants, especially during settlement. I will review research on the relationship between social capital and child wellbeing and offer analysis from a newcomer perspective. I also plan to confirm that children can build their own social capital. I will achieve this by reviewing research that directly measures indicators of children's social capital. I will conclude with recommendations for public policies, programs, and further research needed to support the successful settlement of young newcomers and to help make their future less precarious and more likely to include secure employment and supportive social networks .

\section{What is Social Capital?}

Social capital is an elusive term that has been variously defined (Ferguson, 2006; Leonard, 2005; Gedajlovic et al., 2013). All definitions, however, have their origin in the idea of "capital," which has been defined by The World Bank Group as the "stock of wealth used to promote goods and services"(2004), and characterized elsewhere as "the wealth out of which more wealth comes" (Kilbride, 2000: 6), and as "an economic good and not a natural given" and thus something "constructed through investment and augmented through usage" (Xue, 2008: n.p.). Building on these generic ideas, several types of capital have been defined, including financial, human, cultural, and social capital. These forms of capital are not mutually exclusive. At a particular point in time and for a particular purpose, one type of capital may be more important than another. Research suggests, for example, that social capital (family, friends) is more important than human capital (education, experience) for growing the businesses of nascent entrepreneurs (Davidsson \& Honig, 
2003). Much of the importance of social capital lies in the fact that it can be converted into other forms of capital, especially financial capital (Leonard, 2005).

Definitions of social capital typically focus on "the value embedded in the social relationships of individuals or collectives" and on the "potential resources" flowing from the network of resources possessed by individuals or social units (Gedajlovic et al., 2013: 456). Features include norms, trust, coordination, and cooperation. Generally, there are two types of social capital: bonding and bridging (internal and external connections). Social capital is also said to have two faces: one that is expansive and leads to positive outcomes within society and another that is closed and results in negative outcomes. Capital that is expansive in one context may be closed in another. For newcomers, social capital involves another duality: whether it is valued based on ethnic or mainstream norms.

Fundamentally, ideas about capital are connected to their economic roots. The definition of social capital offered by The World Bank Group (2011) focuses on "norms and networks" at the collective level and points to its long term economic importance to society as a whole:

Social Capital refers to the norms and networks that enable collective action. It encompasses institutions, relationships, and customs that shape the quality and quantity of a society's social interactions. Increasing evidence shows that social capital is critical for societies to prosper economically and for development to be sustainable.

Building upon the idea that capital is constructed and augmented, Gedajlovic et al. (2013) have created a schematic model of social capital and entrepreneurship. This model begins with the antecedents of social capital and flows through relationships and networks to outcomes at both the individual and collective levels. Antecedents include social attributes, cognitive traits, and other individual and organizational factors that promote the development of relationships and networks. The fact that the schema accommodates an antecedent stage for the development of skills and resources for building social capital, as well as stages for the operationalizing of social capital at individual and collective levels within complex environments, makes it a useful model for understanding how the concept of social capital might serve as a framework for supporting the settlement of newcomer children.

\section{Social Capital and Settlement}

Researchers have expressed concerns about the employability of newcomers and the overall ability of many to settle. These concerns, which foreshadow precarious futures for both individuals and society, extend well past what might be understood as the settlement period, into the second and third generation following migration. For example, in a report for the Social Planning Council of Ottawa, the social and economic exclusion of racialized second generation Canadians has been attributed to factors such as the settlement difficulties of parents, poor labour market outcomes, and 
discrimination. It is seen as possibly worse for the second generation than for their parents. The results are described as "a waste of talent and a loss of economic potential" as well as a "weakening of a sense of belonging" (Sorokina, 2013: 10).

\section{Labour Market Outcomes}

In the face of such exclusion, discussions of the role of social capital in the settlement process and of the need for more research in this area acquire new urgency. Kunz (2005), whose definition of social capital focuses on social networks, concludes that social capital has a role in immigrant integration as it can help newcomers get a job (though not necessarily a better job). Kunz emphasizes the value of settlement programs that help newcomers understand rules and norms within the receiving society and promote the development of networks outside their communities, as these programs may be able to facilitate social and economic integration. After an extensive study using data from the Longitudinal Survey of Immigrants to Canada ((LSIC), Xue (2008), concludes that, initially, social capital influences the probability of employment. The development of more ethnically diverse networks may also facilitate the economic assimilation of recent immigrants, although high co-ethnic levels of social capital among immigrant groups may have a negative effect on their labour market outcomes. Jackson (2012) points to a lack of research on the influence of social capital on the settlement process. He argues that while the selection of immigrants is based on human capital and success is measured on a purely economic basis, more work is needed to determine the value of social capital:

... if the basis of selection of immigrants continues to be weighted toward human capital, successful settlement could be further enhanced by additional consideration of social capital. This balance would provide an additional mechanism to validate whether an immigrant's human capital will be realized in a successful settlement experience ( $p$. 18).

In a subsequent presentation (2013), he says that more work is needed to establish "causal linkages" between social capital, human capital and settlement outcomes and "ensure that social capital is considered at each stage" (slide 12).

\section{Educational Outcomes}

When social capital is based on norms and networks that do not reinforce mainstream social norms, it may have a negative or mixed influence on education as well as labour market outcomes. Brankston (2004) points out that for the "investment of social relations to yield a profit, there must be an interaction between those relations and a set of cultural norms." Results are not positive when immigrants form "closed pockets" to protect themselves from other influences. Students whose behavioural patterns are "endorsed by an ethnic immigrant group may suffer rejection by peers and social discrimination" (2004: 177-178). Kao (2004) also considers that social capital 
is manifest as social norms and concludes that social norms provide "rewards for positive behaviour, but exact sanctions for negative behaviour" (2004: 173).

The value of social capital can change over time. Zhou and Kim (2006) describe how ethnic resources and social capital generated by systems of supplementary education within Chinese and Korean communities in the United States, helped immigrants graduate from high school and enter prestigious colleges. Later, however, these resources may have become "constraining" for the children who concentrated on science and engineering because their families were pressuring them and their co-ethnic friends were taking the same subjects. After graduation, they often lacked "the type of social networks that could have facilitated their job placement and occupational mobility" (2006: 21).

Newcomer children, like all newcomers, should not be required to accept one set of norms while rejecting another, nor should they be solely responsible for the acceptance of their social capital by others. To thrive, children from minority cultures must add their own cultural capital to that of the dominant group to create networks reflective of more than one culture. Social institutions such as schools have the power to influence child outcomes positively, by expanding social norms; or negatively, by reinforcing restrictions based on cultural status (Kilbride, 2000: 6-7).

\section{Social Capital and Children}

Discussions of social capital and children must consider whether children have access both to sources of existing social capital and to the skills and resources that will help them accumulate more. The relevance of social capital to children's lives must, therefore, be explored from two perspectives: 1) social capital as it is passed to children from parents and 2) social capital as it is accumulated by children in their own right and available to them and their families. In the following paragraphs, I will consider social capital from the first perspective and provide a brief analysis of the relevance of research findings to newcomer populations. Following this, I will explore the social capital of children in their own right.

\section{Social Capital from Parents}

The relationship between children's wellbeing and the social capital available to them from their parents has been studied extensively in the US. Following a systematic review of 22 pertinent peer-reviewed studies that complied with specific selection criteria, Ferguson (2006) concludes that "a social capital theoretical lens can be beneficial to further explore various outcomes related to children and young people's wellbeing." Her conclusion is based on two premises: 1) that there is empirical evidence that family- and communitybased interactions and relationships can have a positive impact on the wellbeing of children and young people, and 2) that after poverty, social capital has the highest influence on children's development and outcomes (2006:9). 
Ferguson grouped findings from the studies within two general categories: 1) indicators of family social capital (relationships between parents and their children) and 2) community social capital (the family's relationships with the community). In the category of family social capital, she included five indicators:

1. Family structure (i.e., the number parents in the home, the presence of a paternal figure)

2. Quality of parent-child relations

3. Adult's interest in the child

4. Parent's monitoring of the child

5. Extended family exchange and support

In the category of community social capital, she found that the most common measurement instrument was the Social Capital Index, developed by Australian researchers, Onyx and Bullen. The Index assesses eight factors:

1. Participation in the local community

2. Social agency or proactivity in a social context

3. Feelings of trust and safety

4. Neighbourhood connections

5. Family and friend connections

6. Tolerance of diversity

7. Value of life (i.e., feeling valued by society)

8. Work connections (i.e., team feelings)

Additional indicators found in other studies include social support networks, civic engagement in local institutions, trust and safety, the degree of religiosity, and the quality of school and neighbourhood.

Considered together, these family and community indicators create a valuable picture of conditions that are likely to support the wellbeing of children. On the other hand, in certain aspects at least, they represent a characterization of social capital that may be closed to those who are not part of the mainstream from which the indicators are drawn. Ferguson herself comments on their limitations outside the mainstream. In "disadvantaged and disorganized communities" where there is structural poverty, social assets associated with social capital may be "immeasurable by upper-middle class, contemporary, US-based social capital indicators" (2006: 9). The same may be true for families from diverse cultural backgrounds, whether or not poverty is an issue. More appropriate indicators would capture strengths inherent in specific cultural contexts, not simply highlight deficits and differences based on impossible or irrelevant norms. A more sensitive interpretation would point to ways of helping families build social capital that has value in their new environment.

For example, we learn that the fourth indicator of family social capital, "parents' monitoring of the child," is measured by the number of school meetings the parents attend, how many of their children's friends that the parents know by sight/name, and how many of their children's friends' parents that the parents know by sight/name. It is likely that most newcomer families would score low on this indicator. One reason for their low scores might be 
the fact that newcomer parents are often reluctant to go to school meetings. Kilbride indicates that many immigrant students and their families find school "alienating and disempowering" (2000: 9). Practical barriers include lack of language fluency and unfamiliar school routines. Those who are willing to meet with teachers are often busy working. For similar reasons, newcomer parents may have little contact with their children's friends and their families. Opportunities for contact will be especially reduced if their children's school friends do not live close by. To truly measure how newcomer parents monitor the activities of their children, researchers need to formulate new indicators appropriate to newcomer situations and, at the same time, recommend how barriers between families and schools can be reduced.

At times it might seem that newcomer families have an advantage, for example, with respect to the fifth indicator, "extended family exchange/support," but this apparent advantage may in fact promote negative outcomes. This indicator is measured by the number of extended family members at the child's home as well as how often the child interacts with extended family members and visits family members outside the home. While it is likely that the extended family plays a key role in many newcomer families, it is also likely that the social capital created by networks within their own family and ethnic group provides children with social norms that ultimately make it more challenging, not easier, to succeed in mainstream society.

Surveying her findings, Ferguson makes three points: 1) in families with high social capital, children have positive general well-being; 2) it is possible to develop a profile of families with high family and community social capital (albeit, one from an upper-middle class US perspective) and 3)after poverty, social capital is the best predictor of a child's welfare. The latter point is not a new finding. In 2000 in Australia, for example, the Commonwealth Department of Family and Community Services identified social capital as one of five key determinants of social and family well-being (Farrell et al., n.d.).

Ferguson's comments about the relevance of mainstream indicators to impoverished situations signal her recognition that more work is needed to identify a common set of indicators that would apply more broadly. Still, her findings provide a basis for identifying assets that might be available to newcomer children and, at the same time, challenge researchers to review their relevance to the experience of immigrants and refugees.

\section{Social Capital Accumulated by Children}

\section{A New Approach}

Children have not typically been considered in relation to how they use existing social networks or create their own. Leonard (2005) is critical of the "limited treatment of children in existing accounts of social capital" (606) and says that since social capital in the lives of children is generally seen as "a byproduct of their parents' relationships with others," the social capital of children is often "invisible." Further, it is often seen as an "asset" for future benefit, not something "in their lives in the present" (607). One reason for the invisibility of children's social capital is the traditional view that children are 
products of adult socialization. In contrast, she says, the new sociology of childhood emphasizes "children's agency" and acknowledges that children also impact adult society:

The new approach emphasizes children's agency and explores the various ways through which their interactions with adults and each other produces, reproduces, challenges and transforms the nature of childhood and society. Adopting the new approach enables researchers to see interactions between generations as much messier than previously. Rather than the transfer of fixed norms, obligations and expectations which children either accept or reject, interactions between adults and children are likely to produce modified standards and customs for both generations (2005: 607).

Interactions become much "messier" when the complexity of culture and the settlement process are included. At the same time, by acknowledging children's agency and looking to modified outcomes, Leonard is identifying reasons why building the social capital of young newcomers can be an important settlement tool.

\section{An Australian Study Granting Children Agency}

Leonard's views are supported by work carried out in Australia, which grants children agency and shows that they are capable of building measurable social capital. This is capital from which they can draw in the present to support current activities and use as a basis for building positive futures (Tayler et al., 2003). As part of a larger initiative to arrive at new ways of thinking about the provision of early childhood services, researchers in Australia questioned adults and children about their experiences. By including children, they addressed children's interests directly and acknowledged their right to participate in relevant social processes that affected those interests. Conversations with children were structured around the Children's Social Capital Survey, an eight-item survey tool that was adapted, with permission, from the Social Capital Measure developed by Onyx and Bullen and used in several of the studies included in Ferguson's review. The eight questions are understandable for children and relevant to their daily lives:

1. Are you in any clubs or groups?

2. Do you visit friends or relatives very often?

3. Do you get to visit neighbours very often?

4. Do you trust most people?

5. Do you feel safe living in this area?

6. If you saw rubbish in the playground, would you pick it up?

7. If a friend was having difficulty with school work, would you help out?

8. Do you like being with people who are different from you (like from another country)?

Researchers administered the survey and asked additional open-ended questions to 138 rural and urban children, from four to eight years of age, in four different age groups: preschool, Year 1, 2, and 3. Their findings include that children's social capital was higher in the urban than the rural community 
(opposite of parents in a parallel study), that children were "competent informants on their own lives," and that it is important to listen to both children and parents (2003:7-8).

This study confirms that the concept of social capital can provide a valuable framework for understanding how to encourage and support the settlement of newcomer children, including very young children. It shows that social capital can be defined and measured using tools that allow for comparisons with adults. In particular, it shows that children can understand the elements of social capital and behave in ways that are reductive (do not like being with people who are different) or cause social capital to accumulate (visit often, trust, feel safe, pick up rubbish, help a friend). Since I have argued elsewhere that "settlement belongs to the child" and that children's settlement is different from the experience of their parents (Colbert, 2010), evidence that children on their own are able to build networks and establish and understand new norms at a very early age is instructive for those wishing to support the successful settlement of young newcomers.

\section{Conclusions}

Researchers rely on several definitions of social capital, which are all nonetheless based on the formation of relationships and networks. Social capital is accumulated by both individuals and communities and influences social and economic outcomes for individuals and society. The building of social capital may be viewed as a process that begins with acquiring social skills and resources and extends through stages in the growth and development of relationships and networks, to the use social capital in social and economic environments. Social capital may be an especially important asset for newcomers, particularly for those seeking employment in the settlement period. In certain spheres, such as education, the value of social capital to an individual depends on the extent to which it supports accepted social norms and the willingness of social institutions, like schools, to resist adopting exclusionary practices. Based on mainstream ideas of social capital and how it is built in families and communities, newcomer parents may not be able to provide their children with sufficient social assets to ensure long term positive outcomes. It is also apparent that children, even at a young age, are capable of building their own social capital. This in turn means that efforts to help newcomer children accumulate social capital have the potential to support their successful settlement, lead to positive short- and long- term outcomes for them and their families, and reduce the likelihood of precarious futures for all.

\section{Recommendations}

\section{Programs and Public Policy}

Since the concept of social capital as discussed in this paper appears to provide an important framework for achieving positive outcomes for individuals and society, it is important to recognize the accumulation of social capital as a key settlement activity. Specific attention should be given to the "antecedents" of social capital, the skills and resources that make the building 
of social capital possible. Work should be carried out to identify appropriate antecedents for newcomer children and their families, especially during settlement.

Given that newcomer parents may be unable to provide sufficient social capital for themselves or their children, the development and implementation of programs that help children build their own social capital and - in turn empower children to help increase family social capital are of critical importance. In addition, school curricula should be adapted and developed to ensure that children at all levels learn to build and operationalize social capital in diverse settings (e.g., by learning how to make friends, work collectively in teams, and benefit from connections in their daily lives).

Since closed systems with restrictive norms exclude access to those outside their systems and reduce possibilities for collective action, ensuring that the community understands its responsibility to broaden its perspective and expand its understanding of social capital is highly recommended. It is important to recognize that new social capital is built upon a foundation of existing capital and that, as time passes, the process of acquiring new social capital has the potential to expand, not diminish, social norms and networks.

In summary, it is important to recognize that the concept of social capital is a powerful tool with the potential to strengthen outcomes for both newcomers and society as a whole. For newcomers, increasing social capital involves building on existing skills and resources and developing relationships and networks that may be largely independent of language and academic achievement. The building of social capital can begin almost immediately on arrival. For members of the mainstream, accumulation of social capital in diverse contexts opens new opportunities, broadens horizons and, for employers, expands the pool of potential workers. Furthermore, programs and policies that support the development of social capital can be implemented for any age group, including very young children. To benefit fully from the building of social capital, however, more research is needed.

\section{Research}

Research is needed to identify a social capital framework for thinking about children and youth and their futures along a continuum that extends from early childhood to adulthood. A major goal of this research should be to shift perspectives and the language of education at every level, including early childhood. The framework should accommodate the complete social capital process, from identifying the antecedents of social capital through to the outcomes that flow from its presence, with consideration for the contexts in which people live.

Along with the framework, researchers should develop measures of social capital that can be used throughout childhood to identify "red flag" areas where children are vulnerable and design programs to address vulnerability. In particular, research is needed to clarify the role of social capital in the settlement process and to identify relevant indicators of individual and family social capital for newcomers of all ages - both immigrants and refugees. In carrying out this work, researchers should bear in 
mind that settlement is a holistic process that involves more than economic outcomes.

Finally, researchers need to work collaboratively with colleagues in other fields to strengthen the awareness of links between the experience of children and future outcomes for individuals as well as society as a whole.

\section{References}

Bankston, C. 2004. "Social capital, cultural values, immigration, and academic achievement: The host country context and contradictory consequences." Sociology of Education 77 (2): 176-179.

Colbert, J. 2010. Welcoming newcomer children: The settlement of young immigrants and refugees. Guelph, ON: Fairmeadow.

Davidsson, P. \& Honig, B. 2003. "The role of social and human capital among nascent entrepreneurs." Journal of Business Venturing 18 (3): 301-331.

Farrell, A., Tayler, C. \& Tennent, L. n.d. "Social capital and early childhood education." Accessed 12 May 2013 from http://eprints.qut.edu.au/281/1/Perspectives Paper.pdf

Ferguson, K. 2006. "Social capital and children's wellbeing: A critical synthesis of the international social capital literature." International Journal of Social Welfare, 15, 2-18. Accessed 12 May 2013 from http://socialwork.usc.edu/ kmfergus/IJSW Well\%20Being.pdf

Gedajlovic, E., Honig, B., Moore, C., Payne, G., \& Wright, M. 2013, May. "Social capital and entrepreneurship: A schema and research agenda." Entrepreneurship Theory and Practice 37 (3): 455-478.

Jackson, B. 2012. The role of social capital in the settlement of immigrants in Canada. (Final Project Essay, Master of Arts - Integrated Studies).

Athabasca University, Athabasca, Alberta. Accessed 12 May 2013 from http://dtpr.lib.athabascau.ca/action/download.php?filename=mais/700/ BlairJacksonProject.pdf

Jackson, B. 2013. Understanding the role of social capital in assessing settlement outcomes. A presentation for the Canadian Evaluation Society (CES) 2013 Conference, Toronto, Ontario. Accessed 09 September 2013 from http://www.slideshare.net/CesToronto/cesconference-20130608.

Kao, G. 2004. "Social capital and its relevance to minority and immigrant populations." Sociology of Education, 77 (2): 172-183.

Kilbride, K. 2000. A review of the literature on the human, social and cultural capital of immigrant children and their families with implications for teacher education. CERIS Working Paper No. 13. Toronto: Joint Centre of Excellence for Research on Immigration and Settlement.

Kunz, J. 2005. "Orienting newcomers to Canadian society: Social capital and settlement." In Social Capital in Action: Thematic Policy Studies. Ottawa: Policy Research Initiative. Accessed 12 May 2013 from 
www.rapp.ualberta.ca/en/Publications/ /...Sep2005socialcapitalinactio $\underline{\text { n.pdf }}$

Leonard, M. 2005. "Children, childhood and social capital: Exploring the links." BSA Publications Ltd, 39 (4), 605-622.

Sorokina, A. 2013. "Social and economic inclusion for all? Challenges for second generation racialized Canadians." Paper presented at the RCIS Conference on Immigration and Settlement: Precarious Futures? May 15-17.

Tayler, C., Farrell, A. \& Tennent, L. 2003. "Children, communities and social capital: New ways of thinking about early childhood service provision." Paper for Our Children the Future Third Annual Conference, Adelaide, AU, 1-3 May 2003. Accessed 12 May 2013 from http://eprints.qut.edu.au/301/1/Our children conf Adelaide 03.pdf

The World Bank Group. 2004. Beyond Economic Growth Student Workbook: Glossary. Accessed 09 September 2013 from http://www.worldbank.org/depweb/english/beyond/global/glossary.html

The World Bank Group. 2011. Social Capital: Overview. Accessed 22 October 2012 from http://go.worldbank.org/C0QTRW4QF0

Xue, L. 2008. "Social capital and employment entry of recent immigrants to Canada: Evidence from the Longitudinal Survey of Immigrants to Canada (LSIC)." Ottawa: Citizenship and Immigration Canada. Accessed 12 May 2013 from http://www.cic.gc.ca/english/resources/publications/employment/index. $\underline{\text { asp }}$

Zhou, M. \& Kim, S. 2006. "Community forces, social capital, and educational achievement: The case of supplementary education in the Chinese and Korean immigrant communities." Harvard Educational Review 76 (1): 129. 